\title{
On phosphoric acid
}

\section{Gay-Lussac}

To cite this article: M. Gay-Lussac (1829) On phosphoric acid, Philosophical Magazine Series 2, 6:35, 395-395, DOI: $10.1080 / 14786442908675179$

To link to this article: http://dx.doi.org/10.1080/14786442908675179

$$
\text { 曲 Published online: } 14 \text { Jul } 2009 .
$$

Submit your article to this journal ๘
Џ Article views: 2

Q View related articles $\sqsubset$ 
bottom of a small glass tube, after having rolled it up, that it may occupy less space. When heated the mercury is volatilized and conderises in the upper part of the tube, the end of which has been previously drawn out by the lamp. No such effect is produced if the whitening has been occasioned by tin.

M. Orfila concludes, from the above and some other experiments, that the small apparatus invented by Mr. Smithson cannot be depended upon for the detection of small quantities of mercury, unless metallic mercury be separated from the gold by distillation, as above mentioned; because solutions which contain no mercury, but merely a little acid or common salt, produce appearances similar to those effected by mercury. M. Orfila nevertheless admits that the appam ratus may be advantageously used, and will detect very minute quantities of mercury, by first treating the whitened gold with muriatic acid and then subjecting it to distillation.

ON PHOSPHORIC ACID.-BY M, GAY-LUSSAC.

M. Englehart has observed that phosphoric acid recently fused and dissolved in water precipitates albumen; a property which it did not previously possess, and which it loses after having been kept for some time in solution. Lately Mr. Clark has discovered that phosphate of soda exposed to a red heat, acquired new properties. It becomes less soluble, contains less water of crystallization, changes in form, and precipitates nitrate of silver white, whilst before calcination it jrecipitates it yellow.

These two observations by M. Englehart and Mr. Clark appear to possess some analogy; 1 have made some experiments to verify my suspicions.

I took some liquid phosphoric acid which had been during a long time in my laboratory, and having ascertained that it did not precipitate albumen, I saturated a part of it with carbonate of soda; the phosphate which I obtained precipitated nitrate of silver of a yellow colour.

Another portion of the same acid, calcined, and then saturated with soda, precipitated nitrate of silver white. Lastly, calcined phosplate of soda was decomposed by acetate of lead, and the phosphate of lead obtained was decomposed by sulphuretted hydrogen. The phosphoric acid separated precipitated albumen, and combined with soda it precipitated nitrate of silver white.

It results from these observations, that the remarkable change of properties, observed by $\mathrm{Mr}$. Clark in the calcined phosphate of soda, is derived from the same cause which produces the same effect with phosphoric acid in similar circumstances. What proves it still further is, that phosphate of soda and phosphate of ammonia, made with calcined phosphoric acid, precipitate nitrate of silver white, and that common phosphate of potash acquires the same property by calcination. It is remarkable that the modification which phosphoric acid undergoes by heat is much more permanent when it is combined with a base, than when simply dissolved in water. Mr. Clark's opinion of the cause of these phrnomena appears to require some modification. 